\title{
First Korean Working Conditions Survey: A Comparison between South Korea and EU Countries
}

\author{
Jungsun PARK ${ }^{1 *}$ and Naroo LEE ${ }^{1}$ \\ ${ }^{1}$ Occupational Safety and Health Research Institute, Korea Occupational Safety and Health Agency (KOSHA), \\ 34-4 Gusan-dong, Bupyong-gu, Incheon 403-711, Republic of Korea
}

Received May 27, 2008 and accepted September 25, 2008

\begin{abstract}
This report aims to provide an overview of the intensity of work and work satisfaction in Korea by comparing the first Korean Working Conditions Survey with the results of the fourth European Working Conditions Survey in 2005. According to the comparison, Korean workers work longer hours than workers in the majority of EU countries. However, work intensity in the EU 27 was 1.5 times stronger than Korea. In Korea, the rate of violence, bullying and harassment in the workplace is much lower than the EU 27, but in terms of work satisfaction, EU workers responded more positively than Korean workers. The amount of leave in Korean workers was much lower than the EU counterparts, yet the average number of accidentrelated or other work-related leaves was greater in Korean workers than workers in the EU. The pattern of exposure to physical factors, namely the most frequent hazards, such as, repetitive movement and painful or tiring posture, is similar in Korean and EU workers. However, the proportion of each exposure is larger in Korean workers than EU workers. In Korea, the most frequently reported work-related symptoms are musculoskeletal disorders followed by stress and fatigue. These patterns are quite similar in Korea and EU countries.
\end{abstract}

Key words: Korean Working Conditions Survey, European Working Conditions Survey, Work intensity, Work satisfaction, Work-related symptoms, Work-related leave

\section{Introduction}

The workplace has changed dramatically due to the globalization of the economy, use of new information and communications technology, growing diversity in the workplace (e.g. increase in female, older, and higher educated workers) and an increased mental workload. Work itself and work environments play a significant determinant in the health of workers.

The European Foundation's European Working Conditions Survey, conducted every five years, has been providing a valuable insight into quality-of-work issues since 1990. The survey represents an effective means of tracking over time the impact of crucial issues and events: EU enlargement, the aging workforce and pressures associated with an ever-increasing pace of life, competitive-

*To whom correspondence should be addressed. ness, productivity, globalization and restructuring. The survey report contributes to be a source of reference for policymakers and as the basis for further research ${ }^{1)}$. In 2005, the fourth European Working Conditions Survey was carried out simultaneously in 31 countries; the EU 25; the two acceding countries, Bulgaria and Romania; the two candidate countries, Croatia and Turkey; and Norway and Switzerland, which financed their participation in the survey. The number of interviews in EU 27 after quality control was $24,610^{1)}$.

The Korean survey aims to provide an overview of the state of working conditions in Korea, as well as indicating the nature and contents of changes affecting the workforce and the quality of work. The specific objective of the survey is to develop social/occupational health indicators for the working environment.

This report aims to provide an overview of the intensity of work and job satisfaction in Korea by comparing 
the first Korean Working Conditions Survey with the results of the fourth European Working Conditions Survey in 2005 .

\section{Subjects and Methods}

KOSHA carried out its first Korean survey on working conditions in $2006^{2)}$. A representative sample of the economically active population aged 15 to $64 \mathrm{yr}$, i.e. persons who were either employees or self-employed at the time of the interview were selected. Retired and unemployed persons, as well as housewives and students were excluded. The basic sample design is a multi-stage random sampling. The Enumeration Districts in the 2005 Population and Housing Census was used for sampling. The fieldwork was carried out from the 26th of June, 2006 to the 26th of September by Gallop Korea. Out of a total of 46,498 visited households, 10,043 interviews were actually carried out. In general face-to face surveys involving random walk tend to face considerable (and increasing) difficulties in reaching the respondent (not only because of refusals and no response, but because of more mundane problems like difficulties in accessing the building, empty households, etc).

The survey weighting was carried out on the basis of the economically active population, which means that its distribution by region, locality, size, gender, age, economic activity and occupation is identical to that of the active population distribution. The questionnaire contains issues regarding working time, physical risk factors, work organization, impact of work on health, satisfaction with working conditions, and violence-bullying-harassment in the workplace, and so on.

The methodology and survey questionnaire of the first Korean Working Conditions Survey was almost the same as those of the European Working Conditions Survey.

\section{Results and Discussion}

The age and gender distribution of the subjects in Korea

The proportion of men is greater than that of women. The proportion of workers aged $30-49 \mathrm{yr}$ is the highest, followed by the age range of $55 \mathrm{yr}$ or more and $29 \mathrm{yr}$ or below (Table 1).

Working time

Weekly working hours

Korean workers work an average of $51 \mathrm{~h}$ per week compared to the $38.6 \mathrm{~h}$ per week in the EU 27. Since 1991, there has been a clear and consistent trend in the EU towards a reduction in paid working hours, a trend which only slowed in 2005 due to the impact of the enlargement of the EU in 2004, where the new Member
Table 1. Gender and age distribution

\begin{tabular}{cccc}
\hline & & $\mathrm{N}$ & $\%$ \\
\hline \multirow{2}{*}{ Gender } & Male & 5,812 & 57.9 \\
& Female & 4,231 & 42.1 \\
\hline \multirow{2}{*}{ Age } & $15-29$ & 1,563 & 15.6 \\
& $30-49$ & 6,033 & 60.1 \\
& $\geq 50$ & 2,447 & 24.4 \\
\hline
\end{tabular}

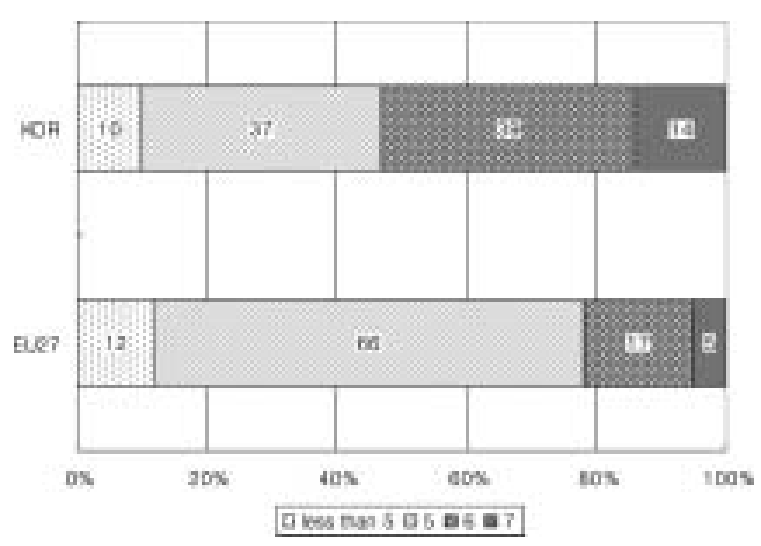

Fig. 1. Number of days worked per week $(\%)$.

States proved to have longer average working hours. Turkey had the longest working hours with $54.1 \mathrm{~h}$ per week.

Number of days worked per week

Fifty-three percent of Korean workers work more than $5 \mathrm{~d}$ per week compared to the $35 \%$ in the EU 27 (Fig. 1). Turkey has a longer working week than most other countries: almost $80 \%$ of Turkish workers work six or seven days. These figures probably reflect the differences in sectoral composition of Turkish economy compared to the rest of Europe, with a much higher proportion of workers in the agricultural sector where working hours are very long.

\section{Long working hours}

Forty-five percent of Korean workers work long working hours (more than $48 \mathrm{~h}$ per week) (Fig. 2) compared to the $15 \%$ in the EU 27 . The country differences in Korea and EU follow the same trends as the figures for average working hours. The sectors most affected by long working hours are agriculture, hotels and restaurants and construction.

\section{Shift work}

Shift work has an important economic function in company operations and a large impact on individual working conditions. 


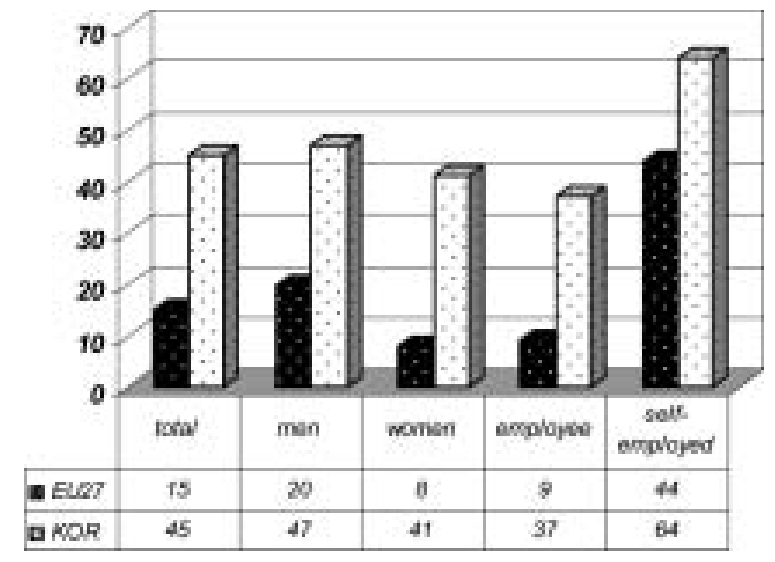

Fig. 2. Long working hours ( $>48 \mathrm{~h}$ per week), by gender and employment status (\%).

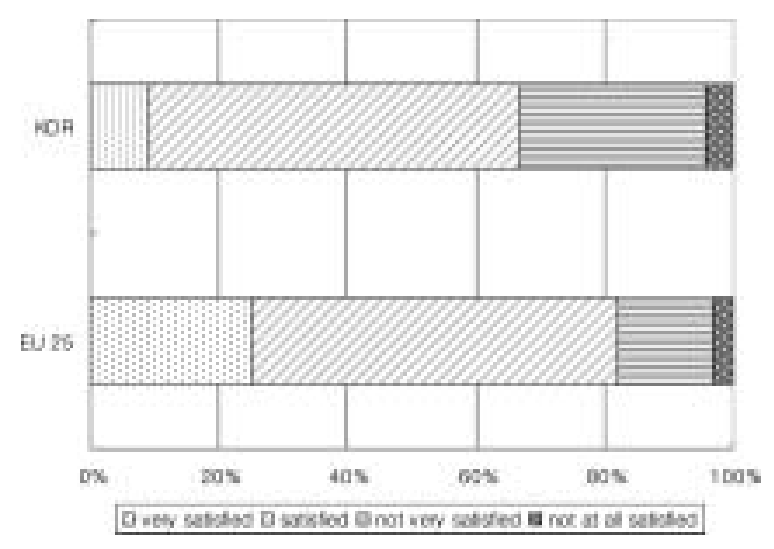

Fig. 3. Work satisfaction (\%).

Approximately $10 \%$ of Korean employees are shift workers, whereas the EU 27 is comprised of $17.3 \%$ of shift workers. The most common type of shift work in Korea is 'rotating 2 shifts' $(50.4 \%)$, followed by 'rotating 3 shifts' (33.7\%), 'daily split shifts' (14.0\%).

The differences between countries in the use of shifts are strongly influenced by the sectoral composition of the economy. In the EU 27, 29\% of the workforce is employed in manufacturing compared to $21.1 \%$ in Korea.

Satisfaction with working conditions

Proportions of work satisfaction

Korean workers were less satisfied at their work than the EU average.

Sixty-seven percent of Korean workers responded as being 'satisfied' or 'very satisfied' with working conditions in their job compared to the $82 \%$ in the EU 27 (Fig. 3). Of course these aggregate figures conceal large differences between countries. In general, national levels of satisfaction with working conditions appear to track closely standard measures of national wealth: countries with higher GDP per person report generally higher lev- els of satisfaction.

\section{Indicators of satisfaction with work}

Estimation on satisfaction according to positive job elements was made. Results showed that Korean workers answered more negatively than the EU average on all 5 items including good friends at work, pay, feel at home, opportunity to learn, and job security except for career advancement. There was an especially big difference in terms of job security (Fig. 4).

\section{Support}

Korean workers were not as supported from colleagues, superiors/boss and external assistance as those in the EU. Twenty-nine percent of workers were supported from colleagues, $23 \%$ were supported from superiors/boss, and $17 \%$ were supported from external assistance (Fig. 5).

Violence, bullying and harassment in the workplace

Less than $1 \%$ of Korean workers say they have experienced physical violence from people within their workplace $(0.3 \%)$ or outside the workplace $(0.6 \%)$, bullying $(0.7 \%)$ or harassment $(0.6 \%)$ in the workplace compared to $25 \mathrm{EU}$ countries showing violence from people within the workplace with $2 \%$, violence from people outside the workplace with $4 \%$, and bullying and harassment with $5 \%$. It is hard to explain why there is such a big difference between Korea and EU solely based on the data of this survey.

\section{Work organization}

Intensity of work

'Intensity of work' indicates 'work demand'. "Intensity of work' index was computed as the average of two indicators: 'working at very high speed' and 'working to tight deadlines'. The index assigns a value of 0 to 'never', 10 to 'almost never', 25 to 'a quarter of the time' 50 to 'around half of the time', 75 to 'around three quarters of the time' 90 to 'almost all of the time', and 100 to 'all of the time'. The work intensity index for Korean workers is $30 \%$ compared to $45 \%$ in the EU 27 .

\section{Autonomy at work}

More than $60 \%$ of Korean workers are able to choose or change the order in which they perform tasks, their speed of work or their working methods. It is similar to the EU 27 with more than $60 \%$.

\section{Physical risk factors}

The term 'physical risk factors' refers to physical risks in the broadest sense, encompassing exposure to physical or ergonomic risks (e.g. work involving painful or tiring positions), biological or chemical risks, as well as to 


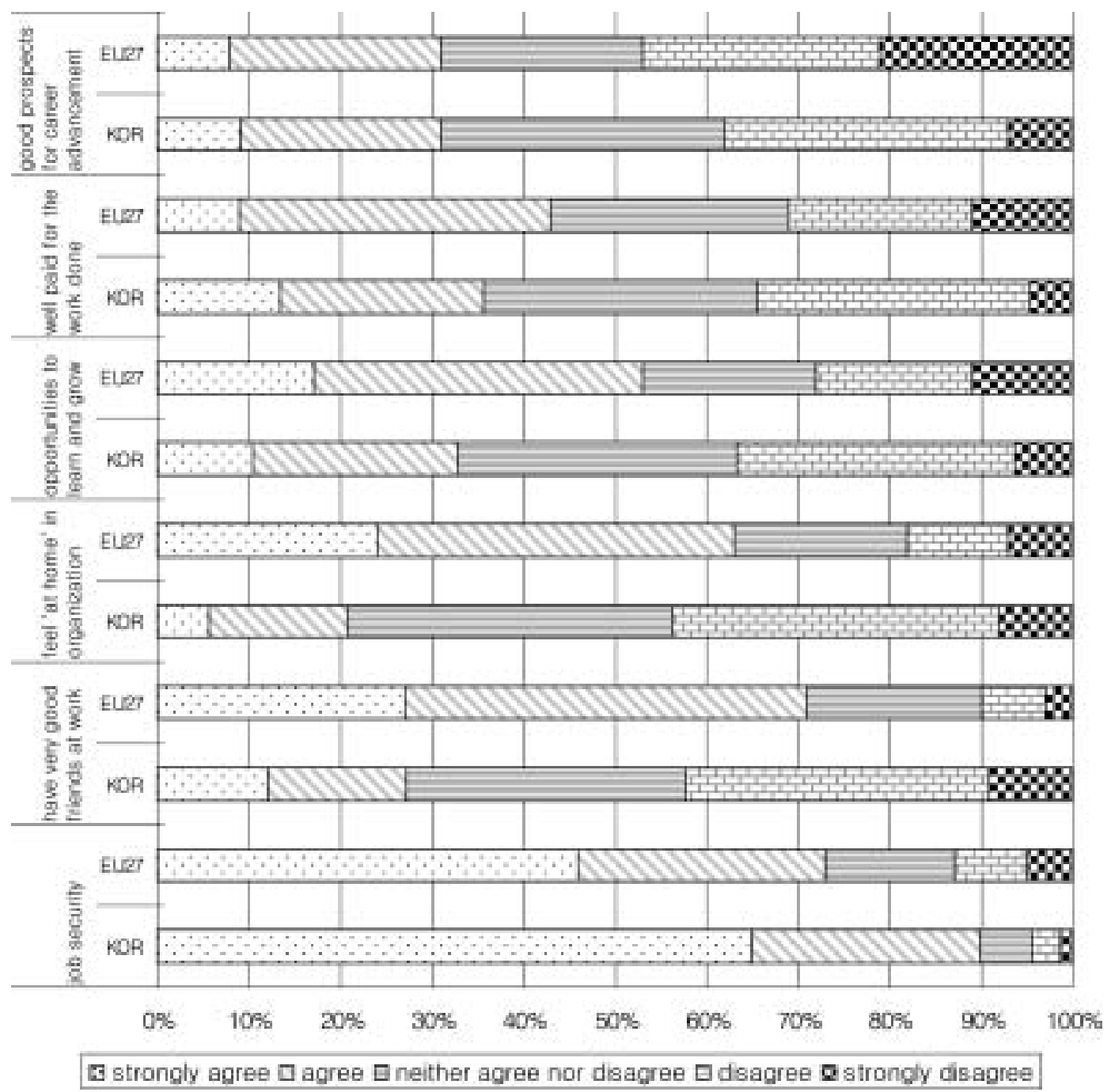

Fig. 4. Satisfaction with positive job elements (\%).

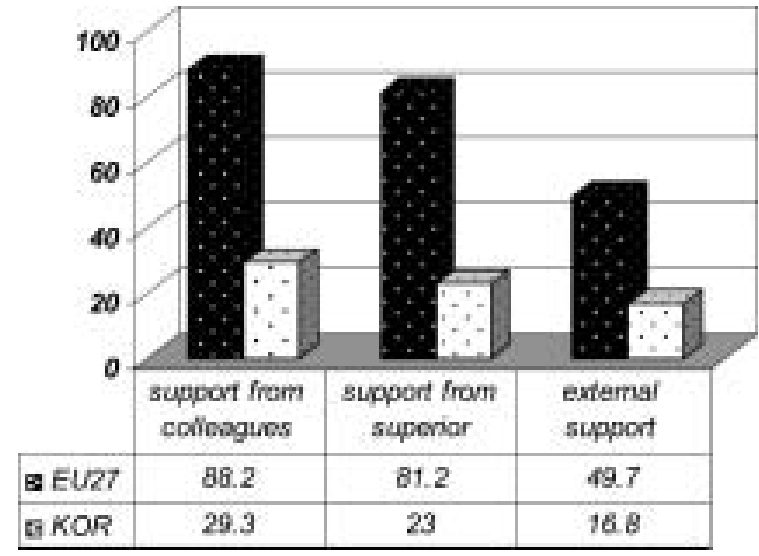

Fig. 5. Social support at work (\%).

ambient or environmental risk factors (e.g. noise, high/low temperatures). 'Radiation' indicates X-rays, radioactive radiation, welding light, and laser beams.
The two most common risks for men and women are repetitive hand/arm movements and working in painful or tiring positions: $71 \%$ make repetitive hand/arm movements a quarter of the time or more, while $61 \%$ work in painful or tiring positions compared to the EU 25 with $62 \%$ and $46 \%$, respectively (Fig. 6). By sector, the most exposed groups in painful or tiring positions are skilled agricultural and fishery workers, services in restaurants, driving and transportation work. This pattern is similar to the EU countries.

Impact of work on health Types of work-related health problems

The Korean survey revealed the most often reported work-related symptoms to be muscular pain (shoulder, neck, upper arms and lower extremities) (18.1\%), followed by stress $(17.9 \%)$, backache $(16.8 \%)$, fatigue $(16.7 \%)$ and headache $(11.2 \%)$. The priority pattern in 


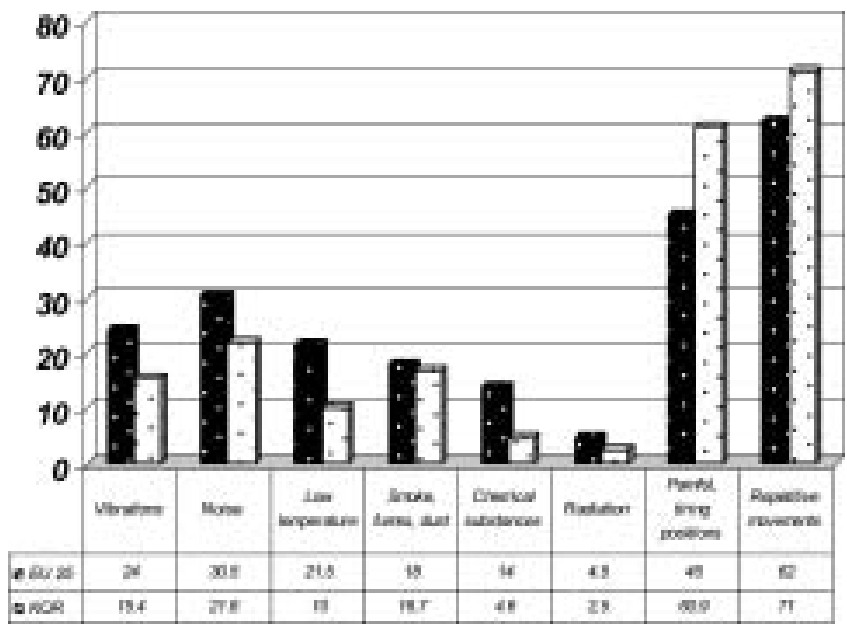

Fig. 6. Exposure to physical risks (\%).

(* proportions exposed a quarter or more of the time).
Table 2. Types of work-related health problems

\begin{tabular}{lrr}
\hline \multicolumn{1}{c}{ Symptom } & $\begin{array}{c}\text { Korea 2006 } \\
\text { (per 100 workers) }\end{array}$ & $\begin{array}{c}\text { EU 27, 2005 } \\
\text { (per 100 workers) }\end{array}$ \\
\hline Muscular pain & 18.1 & 22.8 \\
Stress & 17.9 & 22.3 \\
Backache & 16.8 & 24.7 \\
Fatigue & 16.7 & 22.6 \\
Headache & 11.2 & 15.5 \\
Irritability & not surveyed & 10.5 \\
Injuries & 7.0 & 9.7 \\
Stomach ache & 6.7 & 5.8 \\
Sleeping problems & 5.1 & 8.7 \\
Eyesight problems & 5.1 & 7.8 \\
Skin problems & 4.8 & 6.6 \\
Anxiety & 4.5 & 7.8 \\
Depression & 3.4 & not surveyed \\
Hearing problems & 2.7 & 7.2 \\
Allergies & 2.2 & 4.0 \\
Respiratory problems & 2.0 & not surveyed \\
Heart disease & 1.0 & 2.4 \\
Other & 0.4 & 1.6 \\
\hline
\end{tabular}

Table 3. Health-related leave

\begin{tabular}{lccc}
\hline & $\begin{array}{c}\text { Average no. of days taken } \\
\text { by workers who took at } \\
\text { least one day of leave }\end{array}$ & $\begin{array}{c}\text { Average no. of } \\
\text { accident-related days } \\
\text { taken by workers }\end{array}$ & $\begin{array}{c}\text { Average no. of other } \\
\text { work-related days } \\
\text { taken by workers }\end{array}$ \\
\hline Korea average & 13.4 & 4.2 & 8.0 \\
Men & 15.4 & 6.4 & 7.7 \\
Women & 11.0 & 1.5 & 8.4 \\
\hline EU-27 average & 20.2 & 0.4 & 1.8 \\
Men & 19.2 & 0.5 & 1.8 \\
Women & 21.3 & 0.4 & 1.7 \\
\hline
\end{tabular}

Korea is similar to the EU (Table 2).

\section{Health-related leave}

Number of days of health-related leave in the previous 12-month period is as follows (Table 3). The average number of days taken by Korean workers who took at least one day of leave during the last 12 months is smaller than the EU, but the average number of accident-related or other work-related days taken by Korean workers during the last 12 months is bigger than the average of the EU.

\section{References}

1) European Foundation for the Improvement of Living and Working Conditions (2006) Fourth European Working Conditions Survey. http://www.eurofound. europa.eu/ewco/surveys/index.htm. Accessed May 1, 2008.

2) Park J, Lee N (2006) First Korean Working Conditions Survey. Occupational Safety and Health Research Institute, Korea Occupational Safety and Health Agency (KOSHA), Incheon. 